\title{
Sobrevivência e desenvolvimento in vitro de Cattleya (Orchidaceae) submetida a tratamentos com colchicina
}

\author{
Survival and development in vitro of Cattleya (Orchidaceae) \\ submitted to treatments with different treatments of colchicines
}

\author{
Alessandro Borini Lone ${ }^{1 *}$; Lílian Keiko Unemoto ${ }^{2}$; \\ Lúcia Sadayo Assari Takahashi ${ }^{3}$; Ricardo Tadeu de Faria ${ }^{4}$
}

\begin{abstract}
Resumo
Nas orquidáceas, a poliploidia produz características desejáveis, que se traduzem em aumento das peças florais, grau de suculência, intensificação do colorido, durabilidade e maior resistência das flores. A colchicina como agente indutor de poliploidia em cultura de plantas in vitro tem suas limitações, pois em elevadas concentrações ou tratamentos muito prolongados, torna-se tóxica. O objetivo do trabalho foi avaliar a influência da concentração e do tempo de exposição à colchicina, na sobrevivência e no desenvolvimento in vitro de Cattleya tigrina. Protocormos foram tratados com colchicina em concentrações de 0,5 e $1 \mathrm{~g} . \mathrm{L}^{-1}$ durante 24,48 e 72 horas. Foram avaliados taxa de sobrevivência dos protocormos (\%), porcentagem de plântulas com múltiplas brotações e altura após três e sete meses. Com o aumento da concentração e do tempo de exposição à colchicina houve maior mortalidade e aumento do número de plântulas com múltiplas brotações e altura reduzida.
\end{abstract}

Palavras-chave: Cattleya tigrina, poliploidia, protocormos

\begin{abstract}
Polyploidy produces desirable characteristicsin orchids that are represented by increase of the floral pieces, succulency degree, intensification of color, durability and larger resistance of flowers. The colchicine as polyploidy inductor agent in in vitro culture of plants has limitations, because when in high concentrations or very long treatments, it becomes poisonous for the vegetal tissues. The objective of this research work was to evaluate the influence of concentrations and times of exposition to the colchicine, on the survival and on the in vitro development of Cattleya tigrina. Protocorms were treated with colchicine in the concentrations of 0.5 and 1 g.L.- during 24,48 and 72 hours. There were evaluated the tax of survival of the protocorms (\%), percentage of plantlings with multiple buds and plant height after three and seven months. The increase of the concentration and of the time of exposition to colchicine caused a larger plant mortality and an increase of plantlings with reduced height.
\end{abstract}

Key words: Cattleya tigrina, polyploidy, protocorms

${ }^{1}$ Biólogo, Aluno do Programa de Pós-Graduação em Fitotecnia do Departamento de Agronomia da Universidade Estadual de Londrina/UEL, Londrina, PR.. Bolsista CNPq. E-mail: alone_bio@yahoo.com.br

2 Bióloga, Doutora em Fitotecnia pela Universidade Estadual de Londrina/UEL, Londrina, PR. E-mail: lilianunemoto@yahoo. com.br

3 Engenheira Agrônoma, Professora, Dra. do Departamento de Agronomia da Universidade Estadual de Londrina,/UEL, Londrina, PR. E-mail: sadayo@uel.br

${ }^{4}$ Engenheiro Agrônomo, Professor, Dr. do Departamento de Agronomia da Universidade Estadual de Londrina/UEL, Londrina, PR. E-mail: faria@uel.br

* Autor para correspondência 
A poliploidia pode ser definida como um dos tipos de variações cromossômicas que afetam o conjunto dos cromossomos das células, aumentando o número de jogos cromossômicos presentes em cada uma delas (LACADENA, 1981).

A poliploidia é muito comum entre as plantas e cerca de 30 a $35 \%$ das plantas com flores são poliplóides (STEBBINS, 1971). Trabalhos mais recentes estimam que essa porcentagem seja de 95\% nas pteridófitas e até $80 \%$ nas angiospermas (LEITCH; BENNET, 1997).

Desde a descoberta da ação poliploidizante da colchicina, que no início foi considerada um "elixir do crescimento", os melhoristas tentam utilizar a indução de poliploidia no melhoramento para obter plantas maiores, melhores e mais produtivas (EVANS, 1981).

A colchicina $\left(\mathrm{C}_{22} \mathrm{H}_{25} \mathrm{O}_{6} \mathrm{~N}\right)$, é um alcalóide extraído de sementes e bulbos de uma liliaceae (Conchicum autumnale), com função específica de atuação no final da prófase mitótica, inibindo a formação do fuso mitótico ou formando um fuso abortivo devido à precipitação das proteínas (FARIA; DESTRO, 1999).

Dentre as formas de aplicação existentes, a poliploidização tem sido obtida com maior eficiência in vitro com o uso de explantes como meristemas apicais e axilares, segmentos de hipocótilo, nós cotiledonares, cotilédones, calos, micrósporos e protocormos (GRIESBACH, 1981; HANSEN et al., 1998).

A colchicina, como agente indutor de poliploidia em cultura de plantas in vitro, tem suas limitações, pois em elevadas concentrações ou tratamentos muito prolongados, torna-se tóxica para os tecidos vegetais (HAMIL; SMITH; DODD, 1992). Assim sendo, para cada espécie e tipo de material a ser tratado, a concentração do alcalóide deve ser determinada (VAKILI, 1969).

Nas orquidáceas, a poliploidia produz características desejáveis, que se traduzem em aumento das peças florais, grau de suculência, intensificação do colorido, durabilidade e maior resistência das flores, atributos valorizados na comercialização (WATROUS; WIMBER, 1988).

Segundo Rocha (2008), a Cattleya tigrina ou Cattleya leopoldii, é uma espécie brasileira que ocorre do litoral do Rio Grande do Sul até Pernambuco. A espécie chama atenção pela coloração e número de flores, sendo muito cultivada e comercializada pelos orquidófilos.

O objetivo do trabalho foi avaliar a influência da concentração e do tempo de exposição à colchicina, na sobrevivência e no desenvolvimento in vitro de Cattleya tigrina.

O experimento foi realizado no Laboratório de Fitotecnia da Universidade Estadual de Londrina. Foram utilizados protocormos de Cattleya tigrina A.Rich., obtidos através de semeadura in vitro em meio MS (MURASHIGE; SKOOG, 1962), modificado com metade da concentração dos macronutrientes e acrescido de 1 g. $\mathrm{L}^{-1}$ de carvão ativo, 30g. $\mathrm{L}^{-1}$ de sacarose e $7 \mathrm{~g} . \mathrm{L}^{-1}$ de ágar. Os demais componentes do meio não foram alterados e o $\mathrm{pH}$ foi ajustado para 5,5 antes da autoclavagem.

Os protocormos, com 15 dias de pós germinação, foram retirados do meio MS modificado (de semeadura) e colocados em meio MS líquido não autoclavado, sem adição de carvão ativo e acrescidos de $7 \mathrm{~mL}^{\mathrm{L}} \mathrm{L}^{-1}$ de SaniAgri ${ }^{\mathrm{TM}}$ (principio ativo: ácido peracético) para evitar contaminação por fungos e bactérias. Ao meio MS líquido foi adicionada colchicina nas concentrações de 0,5 e 1g. $\mathrm{L}^{-1}$ e os tempos de exposição dos protocormos à colchicina foram de 24,48 e 72 horas. Como controle utilizaram-se protocormos em meio MS líquido sem adição de colchicina por 72 horas. Após a exposição à colchicina, os protocormos foram lavados em água autoclavada e postos em meio MS modificado, semelhante ao da semeadura, na quantidade de cinco protocormos por frasco, em um total de 10 frascos de vidro por tratamento. Todo o procedimento foi realizado em câmara de fluxo 
laminar para evitar possíveis contaminações. As culturas foram transferidas para sala de crescimento com 2.000 lux de luminosidade, fornecida por lâmpadas fluorescentes de $40 \mathrm{~W}$, fotoperíodo de 16 horas-luz e temperatura de aproximadamente $25 \pm 2$ ${ }^{\circ} \mathrm{C}$.

Dois meses após o tratamento com colchicina foi avaliada a taxa de sobrevivência dos protocormos (\%);, após três meses foram avaliados altura da parte aérea e porcentagem de plântulas com múltiplas brotações e após sete meses foi feita uma nova avaliação de altura da parte aérea das plântulas. Todo o procedimento de avaliação foi realizado em câmara de fluxo laminar para evitar contaminações.

O delineamento experimental utilizado foi $\mathrm{o}$ inteiramente casualizado, com sete tratamentos, 10 repetições e cinco protocormos por parcela. As variáveis referentes à taxa de sobrevivência e plântulas com múltiplas brotações, em porcentagem, foram transformados em arco seno $(\mathrm{x} / 100)^{0,5}$. Foi realizada análise de variância, complementada por comparação das médias com o teste de Scott-Knott, com intervalo de confiança de $5 \%$.
A menor taxa de sobrevivência dos protocormos (32\%) foi verificada no tratamento com colchicina na concentração de 1 g. $\mathrm{L}^{-1}$ no período de 72 horas de exposição, seguido pelo tratamento com concentração de 1g.L-1 por 48 horas (84 \%) (Tabela 1). Não houve diferenças estatísticas para os demais tratamentos em relação ao controle, mostrando que as demais concentrações e tempos de exposição, de modo geral, não apresentaram toxicidade para os protocormos. Esse resultado está de acordo com Hamil, Smith e Dodd (1992), que afirmam que altas concentrações e tratamentos muito prolongados de colchicina podem ser tóxicos para os tecidos vegetais. No entanto Silva, Callegari-Jackes e Zanettini (2000), observaram diferentes respostas para a sobrevivência de variedades de Cattleya intermedia tratadas com diferentes concentrações de colchicina e tempos de exposição, indicando um possível efeito do genótipo na resistência à colchicina. Já Vichiato et al. (2007) obtiveram ausência de morte em plantas de Dendrobium nobile tratadas com colchicina, sugerindo que essa orquídea possui maior resistência aos efeitos nocivos do alcalóide.

Tabela 1. Valores médios da taxa de sobrevivência, porcentagem de plântulas com múltiplas brotações, primeira medição de altura de parte aérea das plântulas (três meses após tratamento com colchicina) $(\mathrm{cm})$ e segunda medição de altura de parte aérea das plântulas (sete meses após tratamento com colchicina) $(\mathrm{cm})$ de Cattleya tigrina, tratadas com diferentes concentrações de colchicina $\left(\mathrm{g} . \mathrm{L}^{-1}\right)$ e diferentes intervalos de tempo (horas).

\begin{tabular}{lcccc}
\hline Tratamentos & $\begin{array}{c}\text { Taxa de Sobrevivência } \\
(\%)\end{array}$ & $\begin{array}{c}\text { Plântulas com } \\
\text { Múltiplas Brotações } \\
(\%)\end{array}$ & $\begin{array}{c}1^{\text {a }} \text { Altura } \\
(\mathrm{cm})\end{array}$ & $\begin{array}{c}2^{\text {a }} \text { Altura } \\
(\mathrm{cm})\end{array}$ \\
\hline Colchicina $-0,5-24 \mathrm{~h}$ & $100 \mathrm{a}$ & $25,55 \mathrm{c}$ & $2,60 \mathrm{a}$ & $3,86 \mathrm{a}$ \\
Colchicina $-0,5-48 \mathrm{~h}$ & $94 \mathrm{a}$ & $22,22 \mathrm{c}$ & $2,65 \mathrm{a}$ & $4,27 \mathrm{a}$ \\
Colchicina $-0,5-72 \mathrm{~h}$ & $100 \mathrm{a}$ & $42,50 \mathrm{~b}$ & $2,39 \mathrm{a}$ & $3,17 \mathrm{~b}$ \\
Colchicina $-1-24 \mathrm{~h}$ & $96 \mathrm{a}$ & $58,88 \mathrm{~b}$ & $2,22 \mathrm{a}$ & $4,23 \mathrm{a}$ \\
Colchicina $-1-48 \mathrm{~h}$ & $84 \mathrm{~b}$ & $75,59 \mathrm{a}$ & $1,88 \mathrm{~b}$ & $2,55 \mathrm{~b}$ \\
Colchicina $-1-72 \mathrm{~h}$ & $32 \mathrm{c}$ & $79,17 \mathrm{a}$ & $1,45 \mathrm{~b}$ & $2,37 \mathrm{~b}$ \\
Colchicina -0 & $100 \mathrm{a}$ & $11,11 \mathrm{c}$ & $2,35 \mathrm{a}$ & $3,66 \mathrm{a}$ \\
CV $(\%)$ & 15,46 & 55,18 & 23,56 & 20,73 \\
\hline
\end{tabular}

Médias seguidas pela mesma letra na coluna não diferem entre si pelo teste Scott-Knott a 5\% de probabilidade 
Observou-se, também, que com o aumento da concentração e do tempo de exposição à colchicina, houve aumento na porcentagem de plântulas com múltiplas brotações (Tabela 1). Unemoto et al. (2009) também obtiveram aumento do número de brotações em Oncidium flexuosum com o aumento do tempo de exposição dos protocormos à colchicina. Silva, Callegari-Jackes e Zanettini (2000) relatam que a colchicina pode ter efeito similar aos efeitos da citocinina, podendo proporcionar proliferação intensa de brotos.

Para altura da parte aérea das plântulas, referente à primeira medição (três meses após o tratamento com colchicina), observou-se tendência de redução com o aumento do tempo de exposição para a concentração de 1 g. $\mathrm{L}^{-1}$, sem diferença entre os demais tratamentos. Já na segunda medição da altura de parte aérea das plântulas (sete meses após o tratamento com colchicina), tanto a concentração de 0,5 g.L.- quanto a de 1 g.L $L^{-1}$ apresentaram redução da altura com o aumento do tempo de exposição. Os tratamentos com colchicina a $0,5 \mathrm{~g} \cdot \mathrm{L}^{-1}$ por períodos de 24 e 48 horas e o tratamento com colchicina a 1 g. L${ }^{1}$ por 24 horas foram os que mostraram as maiores médias de altura, não diferindo estatisticamente do tratamento controle (Tabela 1).

Vichiato et al. (2007) observaram que as plantas poliplóides de Dendrobium nobile obtidas após tratamento com colchicina também expressaram desenvolvimento lento e pouco vigoroso quando comparadas às plantas diplóides. Segundo esses autores o aumento das estruturas vegetativas é encontrado comumente em órgãos de padrão de crescimento altamente determinado, como flores e sementes e, por isso, nem sempre é observado entre plantas com diferentes níveis de ploidia. No entanto, Farinaci (2001), que avaliaram indivíduos diplóides e tetraplóides naturais de Bulbophyllum ipanemense, não observaram modificação morfológica visualmente associada a poliploidia, nem mesmo o aumento no tamanho dos indivíduos.
Os resultados mostraram que com o aumento da concentração, de 0,5 para 1 g. $\mathrm{L}^{-1}$, e do tempo de exposição à colchicina, de 24 a 72 horas, ocasionou maior mortalidade e aumento do número de plântulas com múltiplas brotações e redução na altura das plântulas.

\section{Referências}

EVANS, G. M. Polyploidy and crop improvement. Journal of the Agricultural Society of Wales, Aberystwyth, v. 62, n. 1, p. 93-116, 1981.

FARIA, R. T.; DESTRO, D. Poliploidia. In: DESTRO, D.; MONTALVÁN, R. (Org.). Melhoramento genético de plantas. Londrina: UEL, 1999. v. 1, p. 57-68.

FARINACI, J. S. Variabilidade genética em algumas espécies de Bulbophyllum Thouars (Orchidaceae) de campos rupestres. 2001. Dissertação (Mestrado em Genética e Biologia Molecular) - Departamento de Genética, Evolução e Bioagentes. Universidade Estadual de Campinas. Instituto de Biologia, Campinas.

GRIESBACH, R. J. Colchicine induced polyploidy in Phalaenopsis orchids. Plant Cell Tissue and Organ Culture, Netherlands, v. 1, n. 1, p. 103-107, 1981.

HAMIL, S. D.; SMITH, M. K.; DODD, W. A. In vitro induction banana altotetraploids by colchicine treatment of micropropagated diploids. Australian Journal of Botany, Melbourne, v. 40, n. 6, p. 887-896, 1992.

HANSEN, A. L.; GERTZ, A.; JOERSBO, B.; ANDESRSEN, S. B. Antimicrotubule herbicide for in vitro chromosome doubling in Beta vulgaris L. ovule culture. Euphytica, Wageningen, v. 101, n. 1, p. 231-237, 1998.

LACADENA, J. R. Genética. 3. ed. Madrid: Ed. AGESA, 1981. $1303 \mathrm{p}$.

LEITCH, I. J.; BENNET, M. D. Polyploidy in angiosperms. Trends in Plant Science, Oxford, v. 2, n. 12, p. 470-476, 1997.

MURASHIGE, T.; SKOOG, F. A Revised medium of rapid growth and bioassay with tobacco tissue cultures. Physiologia Plantarum, Sweden, v. 15, n. 3, p. 473-479, 1962.

ROCHA, R. Abc do orquidófilo: de uma, várias ou muitas orquídeas. Viçosa, MG: Agronômica Ceres, 2008. 424 p. 
SILVA, P. A. K. X. M.; CALLEGARI-JACKES, S.; ZANETTINI, M. H. B. Induction and identification of polyploids in Cattleya intermedia Lind. (Orchidaceae) by in vitro techniques. Ciência Rural, Santa Maria, v. 30, n. 1, p. 105-111, 2000.

STEBBINS, G. L. Chromosomal evolution in higher plants. Reading: Addison-Wesley, London, 1971.216 p.

UNEMOTO, L. K.; FARIA, R. T.; DESTRO, D.; BARBOSA, C. M.; LONE, A. B. Sobrevivência e diferenciação de protocormos de Oncidium flexuosum submetidos a tratamento com ácido peracético e colchicina. Acta Scientiarum Agronomy, Maringá, v. 31, n. 3, p. 503-508, 2009.
VAKILI, N. G. The experimental formation of polyploidy and its effect in the genu Musa. American Journal of Botany, Ohio, v. 54, n. 1, p. 24-36, 1969.

VICHIATO, M. R. M.; VICHIATO, M.; PASQUAL, M.; CASTRO, D. M.; DUTRA, L. F. Indução e identificação de tetraplóides em Dendrobium nobile Lindl. (Orchidaceae). Revista Ciência Agronômica, Fortaleza, v. 38, n. 4, p. 385-390, 2007.

WATROUS, S. B.; WINBER, D. E. Artificial induction of polyploidy in Paphiopedilum. Lindleyana, New York, v. 3, n. 4, p. 177-183, 1988. 
